Nouria và F.Abroug. M. Eddleston, F. Worek và cs (Anh) khi nghiên cứu trên 107 BN ngộ độc với profenofos và prothiofos là những phospho hữu cơ độc tính trung bình nhận thấy hoạt tính acetylcholinesterase hông câu và butyrylcholinesterase huyết tương lúc nhập viện không liên quan đến độ nặng lâm sàng. Vì thể không chỉ dựa vào hoạt độ CHE để chẩn đoán mức độ nặng trên lâm sàng cũng như tiên lượng bệnh nhân.

Kết quả nghiên cứu này khác với nghiên cứu của Phạm Duệ ở 20 bệnh nhân ngộ độc phospho hữu cơ (2002) khẳng định: CHE có mối tương quan chặt chẽ với triệu chứng lâm sàng ( $p$ $<0,05)$. Sự khác biệt này là do sự khác biệt trong loại phospho hữu cơ. Các phospho hữu cơ thế hệ mới vào cơ thể chuyển hóa thành oxon là các chất ức chế butyryl cholinesterase rất nặng, ví dụ chất chuyển hóa Chlorpyrofos-oxon ức chế butyryl cholinesterase mạnh hơn acetylcholinesterase $>500$ lần. Do đó hoạt độ butyryl cholinesterase phải giảm rất nặng mới đủ để ức chế acetyl cholinesterase tạo ta các triệu chứng lâm sàng.

\section{KẾT LUÂ̂N}

Các phospho hữu cơ thế hệ mới không có biểu hiện râm rộ của hội chứng cường cholin cấp so với các phospho hữu cơ thế hệ cổ điển.

\section{TÀI LIỆ THAM KHẢO}

1. Jeyaratnam J. Acute pesticide poisoning: a major global health problem. World Health Stat Q Rapp Trimest Stat Sanit Mond. 1990;43(3):139-144.

2. Eyer P. The Role of Oximes in the Management of Organophosphorus Pesticide Poisoning. Toxicol Rev. 2003;22(3):165-190.

3. Wadia RS, Bhirud RH, Gulavani AV, Amin RB. Neurological manifestations of three organophosphate poisons. Indian J Med Res. 1977:460-68.

4. Erdman AR. Insecticides. In: Dart $\mathrm{RC}$, ed. Medical Toxicology. 3rd edn. Lippincott Williams \& Wilkins; 2004.

5. Phạm Duệ. Nghiên cứu kết hợp PAM và atropin trong điều trị ngộ độc cấp thuốc trừ sâu phospho hữu cơ, 2005, Luận Văn Y Học, 8-10.

6. Yurumez $Y$, Durukan $P$, Yavuz $Y$, et al. Acute Organophosphate Poisoning in University Hospital Emergency Room Patients. Intern Med. 2007; 46(13):965-969.

7. Jalali N, Balali-Mood M, Jalali I, Shakeri MT. Electrophysiological Changes in Patients with Acute Organophosphorous Pesticide Poisoning. Basic Clin Pharmacol Toxicol. 2011;108(4):251-255.

8. Phạm Duệ. Nhận xét qua 16 bệnh nhân ngộ độc phospho hữu cơ tử vong tại khoa hồi sức cấp cứu A9 Bệnh viện Bach Mai. Y học thực hành.1991, 14-16

9. Gagarin PY, Rajagopal RL. Clinical profile and outcome of organophosphorus poisoning in a tertiary care centre, a prospective observational study. Int J Med Res Rev. 2020;8(2):148-153.

\title{
ĐÁNH GIÁ KẾT QUẢ ĐẶT STENT TỰ NỞ SUPERA TẠI ĐỘNG MACH KHOEO
}

\section{TÓM TẮT}

Mục tiêu: Mô tả đặc điểm lâm sàng, đặc điểm tổn thương của bệnh nhân Bệnh động mạch chi dưới có hẹp động mạch khoeo và Đánh giá kết quả tức thời của bệnh nhẩn đặt stent Supera tại vị trí động mach khoeo. Phương pháp nghiên cứu: Từ tháng 6/2019 đến tháng $6 / 2021$, nghiên cứu tiến hành trên 33 đối tượng có bệnh động mạch chi dưới và được can thiệp đặt stent Supera taii vị trí động mạch khoeo. Các bệnh nhân được đánh giá lâm sàng, cận lâm sàng trước và sau can thiệp, theo dõi dọc sau 3 tháng. Kết quả nghiên cứu: Tuổi trung bình của nhóm nghiên cứu là $75.8 \pm 10$ tuổi.Tỷ lệ nam/nữ: 3/1. Bệnh nhân nhập

\footnotetext{
${ }^{1}$ Bệnh viện Đa khoa Phúc Lâm

${ }^{2}$ Bềnh viền Bach Mai

Chịu trách nhiệm chính: Nguyễn Hoài Vũ

Email: nguyenvu.1993@gmail.com

Ngày nhận bài: 13.8.2021

Ngày phản biện khoa học: 8.10.2021

Ngày duyệt băi: 18.10.2021
}

\section{Nguyễn Hoài Vũ ${ }^{1}$, Nguyễn Ngọc Quang ${ }^{2}$}

viện ở giai đoạn muộn (giai đoạn III,IV) chiếm tỷ lệ $97 \%$ trong đó tỷ lệ có loét và hoại tử chi thể là $81.8 \%$. Chỉ số huyết áp tâm thu cổ chần- cánh tay ABI cải thiện trước và sau can thiệp $0.53 \pm 0.24$ đến 0.69 \pm 0.21 , huyết áp tâm thu cổ chân tăng từ $65.9 \pm 35.7$ $\mathrm{mmHg}$ lên $88 \pm 28.7$ mmHg có ý nghĩa với $\mathrm{p}<0.0001$. Tỷ lệ tái hẹp sau 3 tháng là $3 \%$.

Tư khóa: Động mạch khoeo, Stent supera, Bệnh động mạch chi dưới.

\section{SUMMARY}

\section{TO EVALUATE RESULTS OF SUPERA STENTS POST DEPLOYMENT}

Objectives: To describe clinical, lesion characteristics of patients with peripheral artery disease in popliteal arteries and to evaluate results of Supera stents post deployment. Methods: From June 2019 to June 2021, we retrospectively the records of 33 patients who received Supera stents in popliteal arteries. Patients were evaluated for clinical before and post stenting, follow-up of 3 months. Results: Mean age was $75.8 \pm 10$ years. Men and women ratio 
was $3: 1$. The grade of rutherford almost was grade III,IV with $97 \%$, prevalance of tissue loss was $81.8 \%$. The mean preoparative ankle-brachial index increased from $0.53 \pm 0.24$ to $0.69 \pm 0.21$ and the mean ankle systolic pressure increased form $65.9 \pm 35.7 \mathrm{mmHg}$ to $88 \pm 28.7 \mathrm{mmHg}$ after intervention $(p<0.0001)$. Instent restenosis was $3 \%$. Conclusions: The implantation of Supera stents in popliteal arteries is effective and safe in treatment of patients with peripheral artery disease.

Key words: Post deployment, Stent supera, Lower extremity artery disease.

\section{I. ĐẶT VẤN ĐỀ}

Bệnh động mạch chi dưới mạn tính là môt bệnh phổ biến trên thế giới hiện nay ${ }^{1}$. Tỷ lệ mắc bểnh động mạch chi dưới mạn tính do xỡ vữa động mạch chiếm 3-7\% dân số1. Tỷ lệ tử vong ở những bệnh nhân được chẩn đoán bệnh động mạch chi dưới khoảng $9 \%{ }^{2}$. Tại Việt Nam, tỷ lệ bệnh động mạch chi dưới đang ngày có xu hướng gia tăng. Thống kê tại Viện Tim mạch Việt Nam cho thây tỷ lệ bệnh nhân bị Bệnh động mạch chi dưới điêu trị nội trú tại Bệnh viện tăng từ $1,7 \%$ (2003) lên tới $2,5 \%$ (2006) và $3,4 \%$ (2007)3. Tương tự với thế giới, bệnh động mạch chi dưới mạn tính ở Việt Nam cũng đang trở thành một gánh nặng về y tế.

Trong thập niên trở lại đây, nhờ sự phát triển của kỹ thuật can thiệp bao gồm:nong bóng, đặt stent đã được khuyển cáo thay thế cho phương pháp phẫu thuật trong điều trị bệnh động mạch chi dưới mạn tính giúp nâng cao hiệu quả điều trị๋. Tuy nhiên, can thiệp tại vị trí động mạch khoeo vẫn còn là môt thách thức khó khăn đối với phương pháp can thiệp đặc biệt đối với những tổn tương dài và phức tạp ${ }^{5}$. Các dụng cụ can thiệp hiện đại mới trong đó đặc biệt là thể hê stent tự nở bằng nitinol đang dịch chuyển xu hướng điều trị tái thông từ phẫu thuật sang can thiệp nội mạch ${ }^{5}$. Đặt Stent tự nở Supera tại động mạch khoeo là kỹ thuật an toàn hơn, tỷ lệ thành công cao $94.7 \%$, giúp bệnh nhân cải thiện triệu chứng, tiên lượng .

ở Viêt Nam, điều trị can thiệp động mạch khoeo bằng phương pháp đặt bằng stent tự nở Supera còn là một kỹ thuật còn mới mẻ, bước đầu được triển khai ở các trung tâm Tim Mạch. Trong điều kiện thực tế, phương pháp vẫn có những vấn đề, khó khăn, thách thức nhưng đạt được những kết quả khả thi ban đầu. Mặc dù vậy, tại Việt Nam, chưa có những nghiên cứu cụ thể nào đánh giá kết quả này. Chính vì thế, nhóm nghiên cứu đã thực hiện nghiên cứu với mục tiêu như trên.

\section{II. ĐỐI TƯỢNG VÀ PHƯƠNG PHÁP NGHIÊN CỨU}

Từ tháng 6/2019 đến tháng 6/2021, nghiên cứu tiến hành trên 33 đối tượng có bệnh động mạch chi dưới và được can thiệp đặt stent Supera tại vị trí động mạch khoeo. Các bệnh nhân được đánh giá lâm sàng, cận lâm sàng, kết quả chụp mạch trước và sau can thiệp, theo dõi dọc tại thời điểm 1 và 3 tháng.

\section{KẾT QUẢ NGHIÊN CỨU}

Phân bố đối tượng theo nhóm tuổi và giới

\begin{tabular}{|c|c|c|c|c|}
\hline \multirow{2}{*}{ Đặc điểm } & \multicolumn{2}{|c|}{ Giới } & \multirow{2}{*}{$\begin{array}{l}\text { Tống } \\
\text { n(\%) }\end{array}$} & \multirow[b]{2}{*}{$\mathbf{p}$} \\
\hline & Nam & Nữ & & \\
\hline Tống n(\%) & 72.7 & 27.3 & 100 & 0.014 \\
\hline $\begin{array}{l}\text { Tuối trung } \\
\text { bình } \\
(X \pm S D)\end{array}$ & $\begin{array}{c}73.9 \\
\pm \\
11.3\end{array}$ & $\begin{array}{c}80.8 \\
\pm 7.8\end{array}$ & $\begin{array}{c}75.8 \pm \\
10.8\end{array}$ & 0.34 \\
\hline
\end{tabular}

Nhận xét: Trong nghiên cứu này, bệnh nhân cao tuổi nhất là 94 tuổi, thấp nhất là 52 tuổi, tuổi trung bình của nhóm nghiên cứu là $75.8 \pm 10.8$ tuổi, tuổi trung bình của nam là $73.9 \pm 11.3$, tuổi trung bình của nữ là $80.8 \pm 7.8$, tuổi trung bình của nam và nữ không có sự khác biệt (với $p=0.34$ ).

Đặc điểm giai đoạn bệnh của các bệnh nhân theo Fountaine

\begin{tabular}{|c|c|c|}
\hline Giai đoạn & Số lượng & Tỷ lệ \\
\hline I n(\%) & 0 & 0 \\
\hline IIa n(\%) & 1 & 3 \\
\hline IIb n(\%) & 0 & 0 \\
\hline III n(\%) & 5 & 15.2 \\
\hline IV n(\%) & 27 & 81.8 \\
\hline Tống n(\%) & $\mathbf{3 3}$ & $\mathbf{1 0 0}$ \\
\hline
\end{tabular}

Nhận xét: Trong nhóm nghiên cứu, các bệnh nhân nhập viện ở giai đoạn sớm (giai đoạn I, IIa,IIb) chiếm tỷ lệ thấp (3\%). Các bệnh nhẩn nhập viện đa số ở các giai đoạn muộn (giai đoạn III, IV), chiếm tỷ lệ 97\%. Trong đó, các bệnh nhân giai đoạn IV (đã có loét hoặc hoại tử chi) chiếm tỷ lệ cao nhất $(81.8 \%)$, sau đó đến các bệnh nhân giai đoạn III (đau khi nghỉ) chiếm tỷ lề $15.2 \%$.

Biến đổi huyết áp tâm thu cổ chân và ABI của các chân được theo dõi sau 3 tháng

\begin{tabular}{|c|c|c|c|}
\hline Thời điếm & HATT cố chân (X ISD) & ABI $(X \pm S D)$ & Phân loại Rutherford \\
\hline Trước can thiệp (1) & $67.8 \pm 40.3$ & $0.53 \pm 0.27$ & \multirow{2}{*}{$4.95 \pm 0.84$} \\
\hline Sau can thiệp (2) & $91.7 \pm 32$ & $0.7 \pm 0.22$ & \\
\hline Sau 1 tháng (3) & $91.6 \pm 32$ & $0.72 \pm 0.21$ & $2.27 \pm 0.7$ \\
\hline Sau 3 tháng (4) & $92.05 \pm 24.8$ & $0.71 \pm 0.2$ & $1.73 \pm 0.82$ \\
\hline
\end{tabular}




\begin{tabular}{|c|c|c|c|}
\hline $\mathrm{p}$ & $\mathrm{p}(1-2)<0.0001$ & $\mathrm{p}(1-2)<0.0001$ & $\mathrm{p}(1-3)=0.05$ \\
& $\mathrm{p}(1-3)<0.0001$ & $\mathrm{p}(1-3)<0.0001$ & $\mathrm{p}(1-4)=0.072$ \\
\hline
\end{tabular}

Nhận xét: Huyết áp tâm thu cổ chân tăng từ $67.8 \pm 40.3$ lên $91.7 \pm 32 \mathrm{mmHg}$ và $\mathrm{ABI}$ tăng từ $0.53 \pm 0.27$ lên $0.7 \pm 0.22$ trước và sau can thiêp có ý nghĩa thống kê với $p<0.0001$, về cải thiện độ Rutherford trước và sau can thiệp giảm có ý nghĩa với $p=0.05$. Sau 1,3 tháng, huyết áp tâm thu cổ chân và $A B I$ không thay đổi nhiều so với thời điểm sau can thiệp với $p<0.0001$. Độ Rutherford có cải thiện đáng kể giữa các thời điểm sau can thiệp, 1 tháng và 3 tháng.

Tái hẹp tại vị trí đặt stent sau 3 tháng

\begin{tabular}{|c|c|c|}
\hline Tái hẹp & Số lượng & Tỷ lệ n (\%) \\
\hline Sau can thiệp & 0 & 0 \\
\hline Sau 1 tháng & 0 & 0 \\
\hline Sau 3 tháng & 1 & 3 \\
\hline
\end{tabular}

Nhận xét: Trong thời gian theo dõi kết quả điều trị 3 tháng, không có bệnh nhân bị tái hẹp trong stent tại thời điểm ngay sau can thiệp và sau can thiệp 1 tháng. Sau 3 tháng can thiệp, số bệnh nhân tái hẹp trong stent là 1 bệnh nhân chiếm tỷ lệ 3\%.

\section{BÀN LUÂN}

Về đặc điểm tuổi giới, bệnh nhân cao tuổi nhất là 94 , thấp nhất là 52 , tuổi trung bình là $75.8 \pm 10$ tuổi.. Trong đó, tuổi trung bình của nữ là $80.8 \pm 7$ tuổi, tuổi trung bình của nam là 73.9 \pm 11.3 , sự tuổi trung bình giữa nam và nữ không có sự khác biệt $(p=0.34)$. Bệnh nhân nam chiếm $72.7 \%$ cao hơn nữ là $27.3 \%$. Tỷ lệ nam/nữ là $3 / 1$. Kết quả này hoàn toàn cao hơn với nghiên cứu Leigzig, với tỷ lệ nam là $52.8 \%$ và tỷ lệ nam/nữ là $1 / 1^{7}$.

Về phân độ Rutherford, các bệnh nhân nhập viện ở giai đoạn sớm (giai đoạn I, IIa,IIb) chiểm tỷ lệ thấp (3\%). Các bệnh nhần nhập viện đa số ở các giai đoạn muộn (giai đoạn III, IV), chiếm tỷ lệ $97 \%$. Trong đó, các bênh nhân giai đoạn IV (đã có loét hoặc hoại tử chi) chiếm tỷ lệ cao nhất $(81.8 \%)$, sau đó đến các bệnh nhân giai đoạn III (đau khi nghỉ) chiếm tỷ lệ $15.2 \%$. Có thể giải thích do ý thức về bệnh của bệnh nhân chưa cao. Đa số đến viện với triệu chứng của hoại tử chi hoăcc đau chân nhiều.

Đánh giá kết quả điều trị, huyết áp tâm thu cổ chân tăng từ $67.8 \pm 40.3$ lên $91.7 \pm 32$ $\mathrm{mmHg}$ và $A B I$ tăng từ $0.53 \pm 0.27$ lên $0.7 \pm 0.22$ trước và sau can thiêpp có ý nghĩa thống kê với $\mathrm{p}<0.0001$, về cải thiện độ Rutherford trước và sau can thiệp giảm có ý nghĩa với $p=0.05$. Sau 1,3 tháng, huyết áp tâm thu cổ chân và $A B I$ không thay đổi nhiều so với thời điểm sau can thiệp với $\mathrm{p}<0.0001$. Độ Rutherford có cải thiện đáng kể giữa các thời điểm sau can thiệp, 1 tháng và 3 tháng.

Độ Rutherford có cải thiện đáng kể giữa các thời điểm sau can thiệp, 1 tháng và 3 tháng. Kết quả này hoàn toàn phù với với các tác giả Enrique với chỉ số $A B I$ cải thiện từ $0.38 \pm 0.37$ lên $0.63 \pm 0.86$ với $p=0.014^{8}$ và tác giả Dierk với chỉ số $A B I$ tăng từ $0.68 \pm 0.14$ lên $0.87 \pm 0.10$ với $\mathrm{p}=0.0001^{9}$.

Sau 1 tháng, không có bệnh nhân bị tái hẹp trong stent tại thời điểm ngay sau can thiệp và sau can thiệp 1 tháng. Sau 3 tháng can thiệp, số bệnh nhân tái hẹp trong stent là 1 bệnh nhân chiếm tỷ lệ $3 \%$. Tỷ lệ tái thông sau 1 tháng là $100 \%$ và sau 3 tháng là $97 \%$.

\section{KẾT LUÂ̂N}

Tuổi trung bình của nhóm nghiên cứu là 75.8 \pm 10 tuổi. Tỷ lệ nam/nữ: 3/1. Bệnh nhân nhập viện ở giai đoạn muộn (giai đoạn III,IV) chiếm tỷ lệ $97 \%$ trong đó tỷ lệ có loét và hoại tử chi thể là $81.8 \%$. Chỉ số huyết áp tâm thu cổ chân- cánh tay $A B I$ cải thiện trước và sau can thiệp $0.53 \pm$ 0.24 đến $0.69 \pm 0.21$, huyết áp tâm thu cổ chân tăng từ $65.9 \pm 35.7 \mathrm{mmHg}$ lên $88 \pm 28.7 \mathrm{mmHg}$ có ý nghĩa với $\mathrm{p}<0.0001$. Tỷ lệ tái hẹp trong stent tại thời điểm 3 tháng là $3 \%$.

\section{KIẾN NGH!:}

Can thiệp đặt stent Supera là phương pháp an toàn, hiệu quả có thể áp dụng vào thực hành lâm sàng.

\section{TÀI LIẸU THAM KHẢO}

1. Malyar N, Fürstenberg $T$, Wellmann $J$, et al. Recent trends in morbidity and in-hospital outcomes of in-patients with peripheral arterial disease: a nationwide population-based analysis. European heart journal. 2013;34(34):2706-2714.

2. Mustapha JA, Katzen BT, Neville RF, et al. Determinants of long-term outcomes and costs in the management of critical limb ischemia: a population-based cohort study. Journal of the American Heart Association. 2018;7(16):e009724.

3. Nguyễn Hữu Tuấn. Nghiên cứu đặc điểm lâm sàng, cân lâm sàng ở bệnh nhân bị bệnh động mạch chi dưới mạn tính. Luận văn thạc sĩ y học, Trường Đại học Y Hà Nội, Hà Nội. 2008.

4. Zeller T. Current state of endovascular treatment of femoro-popliteal artery disease. Vascular Medicine. 2007;12(3):223-234.

5. Das T. Optimal therapeutic approaches to femoropopliteal artery intervention. Catheterization 
and cardiovascular interventions. 2004;63(1):21-30.

6. San Norberto EM, Flota CM, FidalgoDomingos L, Taylor JH, Vaquero C. Real-world results of supera stent implantation for popliteal artery atherosclerotic lesions: 3-year outcome. Annals of vascular surgery. 2020;62:397-405.

7. Scheinert $D$, Werner $M$, Scheinert $S$, et al. Treatment of complex atherosclerotic popliteal artery disease with a new self-expanding interwoven nitinol stent: 12-month results of the Leipzig SUPERA popliteal artery stent registry.
JACC: Cardiovascular Interventions. 2013;6(1):65-71.

8. Norberto EMS. Impact of Implantation Defects on Intermediate Outcome of Supera Stent for Popliteal Artery Stenosis. Annals of Vascular Surgery. 2017;41:186-195.

9. Scheinert D, Grummt L, Piorkowski M, et al. A novel self-expanding interwoven nitinol stent for complex femoropopliteal lesions: 24-month results of the SUPERA SFA registry. Journal of Endovascular Therapy. 2011;18(6):745-752.

\section{BƯớC ĐẦU ĐÁNH GIÁ KẾT QUẢ HÓA-XA TRI ĐÔNNG THỜI UNG THƯ PHỔI TẾ BÀO NHỎ GIAI ĐOÂN II, III TẠI BỆNH VIỆN PHỔI TRUNG ƯO'NG 2016-2020}

\author{
Bùi Mỹ Hạnh ${ }^{1}$, Nguyễn Thành Công ${ }^{1}$, \\ Đặng Văn Khiêm² ${ }^{2}$ Lê Tú Linh ${ }^{2}$
}

\section{TÓM TẮT}

Bước đầu đánh giá kết quả điều trị ung thư phổi tế bào nhỏ giai đoan II, III bằng phương pháp hóa xạ trị đồng thời tại bệnh viện phối trung ương năm 20162020. Đối tượng và phương pháp nghiên cứu: Quan sát thử nghiệm lâm sàng hồi cứu không đối chứng trên 71 bênh nhân ung thư phổi tế bào nhỏ giai đoan II, III nhận điều trị hóa xạ trị đồng thời với carboplatin và etoposide tại khoa ung bướu bệnh viện Phổi trung ương thời gian từ 01/01/2016-31/12/2020. Kết quả: tuổi trung bình $58,79 \pm 9,26$, tỷ lệ nam/nữ 34/1, chỉ số toàn trang $\mathrm{PS}=0(50 / 71,70,42 \%), \quad \mathrm{PS}=1 \quad(21 / 71$, $29,58 \%)$, phân loại TNM chủ yếu giai đoạn III (69/71, $97,18 \%)$, trong đó IIIB (36/71, 50,70\%), IIIC (28/71, $39,44 \%)$. Đáp ứng hoàn toàn $(12 / 71,16,90 \%)$, đáp ứng một phần $(45 / 71,63,38 \%)$, đáp ứng toàn bộ (57/71, 80,28\%) bệnh ổn định $(3 / 71,4,23 \%)$, bệnh tiến triển $(11 / 71,15,49 \%)$. Thời gian theo dối trung bình là 32 tháng, thời gian sống thêm không tiến triển (PFS) trung bình là 16,4 tháng, thời gian sông toàn bô (OS) trung bình là 25 tháng, OS bị ảnh hưởng bởi các yếu tố tuổi, PS. Độc tính cấp trên huyết học đô̂ 3,4 và 5 chiếm tỷ lệ khá cao $(25 / 71,35,21 \%)$. Độc tính ngoài huyết hoc tỷ lể rất thâp chủ yếu là độ 1 và độ 2 , trên độ 3 chí có viểm phổi chiếm (3/71, 4,23\%), sốt giảm bạch cầu $(5 / 71,7,05 \%)$. Kết quả bước đâuu điều trị ung thư phổi tế bào nhỏ giai đoạn II, III bằng phương pháp hóa xạ trị đồng thời cho thấy hiệu quả và tính an toàn cao. bào nhỏ

Tư khóa: Hóa xạ trị đồng thời, ung thư phổi tế

\footnotetext{
${ }^{1}$ Trường Đại học Y Hà Nội

${ }^{2}$ Bệnh viện phổi trung ương

Chịu trách nhiệm chính: Bùi Mỹ Hạnh

Email: buimyhanh@hmu.edu.vn

Ngày nhận bài: 17.8.2021

Ngày phản biên khoa họ: 12.10.2021

Ngày duyệt bài: 19.10.2021
}

\section{SUMMARY \\ INITIAL ASSESSMENT OF TREATMENT \\ RESULTS FOR STAGE II, III SMALL CELL LUNG CANCER BY CONCURRENT CHEMORADIOTHERAPY AT THE NATIONAL LUNG HOSPITAL IN 2016-2020}

Initial assessment of treatment results for stage II, III small cell lung cancer by concurrent chemoradiotherapy at the National Lung Hospital in 2016-2020. Subjects and methods: Observation of an uncontrolled retrospective clinical trial, we enrolled 71 patients with stage II, III small cell lung cancer to be recieved concurrent chemoradiotherapy with carboplatin and etoposide at the oncology department at National Lung Hospital from January 1, 2016 to December 31, 2020. Results: Median age 58.79 \pm 9.26 , male/female ratio $34 / 1$, performance status $(P S)=0$ $(50 / 71,70.42 \%), P S=1(21 / 71,29.58 \%)$, mainly TNM stage III $(69 / 71,97.18 \%)$ with IIIB $(36 / 71,50.70 \%)$ and IIIC (28/71, 39.44\%). Complete response (12/71, $16.90 \%)$, partial response $(45 / 71,63.38 \%)$, overall response rate $(57 / 71,80.28 \%)$, stable disease $(3 / 71$, $4.23 \%$, progressive disease $(11 / 71,15.49 \%)$. The median follow-up period was 32 months, median progression-free survival (PFS) was 16.4 months and median overall survival (OS) was 25 months, OS was affected by some factors such as age, PS. Acute hematological toxicity grade 3,4 and 5 accounted for a fairly high rate ( $25 / 71,35.21 \%)$. Non-hematological toxicity rates were very low, mainly grade 1 and grade 2 , above grade 3 pneumonia (3/71, 4.23\%), fever with leukopenia $(5 / 71,7.05 \%)$. Initial results of treatment of stage II, III small cell lung cancer by chemoradiotherapy was high efficiency and safety.

Keywords: Concurrent chemoradiotherapy, small cell lung cancer.

\section{I. ĐẶT VẤN ĐỀ}

Ung thư phổi tế bào nhỏ (UTPTBN) là loại ung thư phổi tiên lượng xấu nhất trong các loại 